\title{
Big Five Traits: A Critical Review
}

\author{
Najm Abood
}

Al Zaytoonah University of Jordan, Jordan

\begin{abstract}
This study seeks to provide a broad and thorough review of the literature on the big five traits (BFT) through a long history of conceptual and applied studies in many areas depending on large samples of individuals, groups and countries. The BFT is the most widely accepted model to describe the structure of personality traits, so this study sought to identify them in order to achieve a better understanding as well as for consideration by researchers in their future studies. This review focused on the eight key observations related to the BFT. These observations are: meaning of the traits; the history of the BFT model; unity or hierarchy of traits; number of the traits; three perspectives on BFT; BFT questionnaires; BFT and performance; and the need for a sixth trait. The results of the study clearly confirmed that there are problems with universal models that tend to generalize a limited number of dimensions in order to interpret personality across borders and cultures.
\end{abstract}

Key words: big five traits (BFT); BFT perspective; number of traits; religiosity; sixth trait

JEL classification: M14 


\section{Introduction}

The theory of traits is one of most important theories of personality (Ewen 2003), and the big five traits (BFT) represent the heart of the theory of personality traits to descript, interpret, and predict human behavior. BFT (extraversion, agreeableness, conscientiousness, openness, and neuroticism or emotional stability) can be considered one of the richest fields of research and development. This can be attributed to three important reasons at least namely, the $B F T$ is the most widely accepted and most prominent model to describe the structure of personality traits (Rammstedt et al. 2010). A large number of studies have addressed the big five traits. Secondly, they cover a broad scope of traits, attitudes, and behaviors related to personality. Thirdly, due to their broad scope, the BFT can serve as an important base for generalizing personality traits cross-cultures and environments as they are supported by an extensive empirical literature (Krueger and Eaton 2010). They also achieve a conceptual and practical importance that stem from the fact that personality traits are relatively stable over time and across situations. They are easy to understand and they have been identified accurately as mutually exclusive categories. Also, the understandability of the BFTs and the easiness of memorizing them represents an opportunity for many people to understand human personality. Lexical studies of personality traits have been replicated in several languages (Rammstedt et al. 2010; Randy et al. 2008: p580), including Czech, Dutch, French, German, Hungarian, Italian, Korean, and Polish (Widiger and Mullins-Sweatt 2005: p40). the BFT questionnaire was translated from English into 28 languages (Schmitt et al. 2007). In this context, the advantage of the BFTs theory is twofold: first, comparability to the other five basic theories of personality: the psychoanalytic, psychoanalytic-social, learning, the cognitive learning social, and humanistic theories (Cloninger 2004). On the other hand, the BFT model stimulated the development of other big trait models such as two big traits (Robertson 1994), big three traits. dark triad, (Paulhus and Williams 2002), big four traits (Cloninger and Svrakic 1997), other big five traits (McAdams and Pals 2006), big six traits (Ashton et al. 2004; Ashton and Lee 2008), big seven traits, and ten traits (Paunonen 2002). The BFT has the ability to provide a valid and adequate framework to assess the personality's psychopathology (Bagby 2005). They also motivate other studies to adopt new five traits in the same field (McAdams and Pals 2006), and other traits (sincerity, excitement, competence, sophistication, and ruggedness) in the brand personality (Aaker 1997).

In general, there is too much reliance on the BFT model (Jang et al. 1996), and its superiority is a result of the inclusion of a broader variety of personality traits and scales (Aziz and Jackson 2001). Nowadays, this model represents the most popular for describing the structure of personality depending on lexicon hypothesis of different languages (Goldberg 2001; Zhou et al. 2009). According to Saucier and Goldberg (1998), all traits of personality can be included in the big five, or fit under their umbrella, such that there is nothing beyond the big five traits nor do they have any alternatives. However, in my view, BFT theory and its components, such as the questionnaires, personality inventory, their empirical evidence, and the results of their application, do not tell the whole story. 
This perspective also explains that many studies have attempted to increase the number of big traits or even provide other traits. This study's purpose is twofold: the first includes an extensive review of the literature on the BFT and the sixth trait that has been added to them, that is religiosity, the second focuses on eight observations and criticisms of the BFTs. This paper is a conceptual study that relies on the critical review of the BFT to identify the critical observations on BFT. Methodologically, this study has been designed as follows: (i) providing a background on the BFT story (the importance of the BFT in personality theories); (ii) a presentation of critical observations on BFT through a thorough review of the literature; (iii) results and discussion; (iv) conclusions; and (v) limitations of the study.

\section{The Story of the Big Five Traits}

Personality is the biological and cultural blueprinting of man, a unique combination of the genetics and the environment. In the terms of evolution, personality is a pattern of unique combination between a biology, psychology, sociology through unprecedented overlap of natural and social selection to form the world of individuals. Despite the great development of our experience in the study of personality, it remains one of the most enigmatic subjets. Personality is the whole complex of the mutual influence of human nature (heredity) and what is expressed in distinct configurations of personality in different contexts (culture). The mystery of personality in other context of analysis (Taylor 2009; Charles 2013), as it seems to us, has become less complicated with the theory of personality traits and in particular with the BFT model. However, the concept of a trait is not easy to determine, and there are serious disagreements about what a trait means (Carver and Scheier 2012: p53). Therefore, any attempt to improve our perceptions of personality, and to increase understanding of it, quickly becomes important in the study of personality. In this context, the Five Big traits represent the best description of personality (Feldman 2013) and appear to be the most exciting in the expression and interpretation of personality and most useful in describing differences between individuals and groups. Many aspects of the BFT model have been studied extensively over the past decades. Some important aspects of them need to be highlighted, such as: the meaning of the trait, the history of the Big Five traits, the hierarchy of traits, the number of the traits, three perspectives regarding BFT, questionnaires for the BFTs, factor structure, the BFTs and performance, and the sixth trait. These aspects are presented below.

\section{History}

In developing the Big Five Traits, the beginning was with the language that represented the repository of the most comprehensive and diverse traits. So, the starting point in the development of the Big Five were adjectives in natural language. The lexical hypothesis is based on the most important phenotypic traits tend to be encoded as single words in natural language (Goldberg 1981; Zhou et al. 2009). According to John and Srivastava (1999), the lexical vision can bring us back to Klages (1926), and Baumgarten (1933). Allport and Odbert's study (1936), cited in John and Srivastava (1999) identified 18,000 terms, this number decreased to 4,500 in the Catell's study (1943), and then to 240 in the Costa and McCrae's study (1992). In- 
deed, the important evolution of BFT is the transition from the lexical vision (dictionary terms, and adjectives) to traits vision where traits are focal points that represent the common characteristics of personality. This development can be traced back to Fiske (1949), cited in Larsen and Buss (2014). In the 1980s, the five traits achieved wide recognition as one of the major theories of personality (Cloninger 2004). Today, the BFT represent one of the important theories in describing and interpreting personality.

The methodological sources for study of personality allocate a wide range to BFT theory as an important area for the evolution of personality study. Finally, though the five major traits have contributed to the study and understanding of personality, the mystery of personality remains greater than one model or theory to tell the whole story. This is evidenced by the fact that increasing our experience in BFT studies and their use in the study of personality has been accompanied by increased criticism of these traits (Eysenck 1992; and McCrae 2009).

\section{The Meaning of Trait}

It is necessary to define the meaning of a trait because it is the basis for interpreting the personality in this study. According to Merriam Webster, traits (character) are what make up and distinguish an individual. It is a complex combination of mental and ethical traits marking and often individualizing a person. A trait is an inner desire of the individual that affects his behavior frequently. It represents a purely descriptive summation of a part of the personality and its related behavior (Larsen: $\mathrm{p}$ 59). It is a recurring pattern of response to things, events, and circumstances. This pat- tern of response is the most significant aspect of personality as an explanatory factor of personality and behavior. According to Cervone and Pervin (2013: p. 232) personality traits have two connotations: consistency (a regularity in the person's behavior) and distinctiveness (traits determine the characteristics which mean people are different). These two connotations give personal traits their scientific importance in describing, interpreting, and predicting human behavior. In the same context, McCrae and Costa (1997) confirm that the trait is "person's typical style of thinking, feeling, and acting in different kinds of situations and at different times" and each trait is a personality dimension which represents a most essential way in which people vary (Costa and McCrae 1988). The theory of personality traits is based on three assumptions. First, personality traits are relatively stable over time. Second, they are stable across different situations (Burger 2011: p.150). Three, the availability of any trait in the individual or group helps to predict certain behaviors associated with this trait.

However, the availability of the trait can be a problem because there is no case where there is a black or white choice, or between presence or absence of the whole trait, but a wide range of behaviors that fall on a continuum of presence of the trait in the individual or group (Burger 2011: p. 150).

The availability of each trait in individuals does not represent an either/or situation. Each trait is not subject to phrasing that implies two options either black or white, which means that either the total presence or total absence of the trait. Instead, the trait can be distributed as multiple levels on a long continuum that rep- 
resents a wide range of behaviors that indicate its availability in individuals. For this reason, there is no pure trait regardless of whether that trait is extraversion or agreeableness or others. In any case, the trait can be a strong determinant of personality as well as of individual differences when the trait is largely present unlike other individuals who lack the same trait significantly.

\section{The Hierarchy of Traits}

Eysenck's hierarchical view of dimensions reveals that the big trait of extraversion (i.e. the supertrait at top level) includes several traits (sociability, liveliness, activeness, and dominance) which in turn include a set of habits, and the latter are also associated with specific stimulus and responses (Carver and Scheier 2012: p. 58; Burger 2011: p. 224). The hierarchy of the Big Five traits contributes to highlighting the subtraits that turn into focal points rather than supertraits. Therefore, this hierarchical structure increases the complexity because the sub-traits are numerous and can be distinguished from each other even though they are sub-components of the same trait. This hierarchy and this division lead to greater complexity without necessarily enriching our understanding of personality. The evolution of the Big Five traits started with represents a transition from a to seeing the big traits as focal points to interpret the characteristics of personality and perhaps predict behavior.

Goldberg (1992) is the one who named the Big Five Traits. He stressed that each of these five traits is vast in terms of interpreting the characteristics of personality. These broad features caused Goldberg to be inclined to use another method of measurement, the bipolar adjec- tive scales. It is clear that these bipolar traits help to avoid a hierarchy of the trait on the one hand, and achieve the distribution of individuals on a continuum that tends to trait (such as extinctions) on the first side and extend on the same continuum to the another side to represent the other side of the trait (introversion). The hierarchical structure of each trait helps to transform it into a focal point to describe personality by these traits. While the bipolar adjective scales lead to the spread of individuals over a wide range of continuum which indicate large differences between individuals in each of Big Five traits.

\section{The Number of Traits}

There has always been a tendency to search for new traits or sub-traits. In fact, this research is a temptation for the writers to put their own touches on the study of personality or take into account additional personality traits that are more important from their point of view. Perhaps the question that can be asked here is this: why are there the Big Five Traits and not any other number? The number five seems to occur and get used frequently in our studies. There are five needs in the Maslow's (1978) Hierarchy of Needs, five sources of power (Raven 1992), and five dimensions of national culture according to Hofstede (after adding the fifth dimension under the influence of Confucianism) (Najm 2015). McCrae and John (1991) point out that the theory of BFT is puzzling and the number of traits may be a historical coincidence. Despite the importance of the number five in managerial studies, some researchers have tended to adopt another number with the so-called plus or minus two traits (Briggs 1989), which means increasing the number 
of traits because there are some missing (Miserandino 2012) or a decreasing number (Eysenck's big three traits). Many studies have identified another number of personality traits such as: Robertson's big two traits (1994), Eysenck's big three traits (1967, 1992), Cloninger and Svrakic's (1997) big four traits, Lee et al. (2005) big six traits, the big seven traits of the Hogen Personality Inventory (1992) and Paunonen and Jackson's big ten traits (2000). Moreover, the impact of BFT has also shifted to other areas and countries such as with Psychopathology Five (PSY5), (Harkness et al. 2002), Alternative FiveFactor Model (2012), and Chinese Personality Assessment Inventory (CPAI),
Cheung et al. (1996) (see Table 1). These differences in the number of traits, as well as in the adoption of different traits, leads to many outcomes such as weakening the consensus on the BFT, and the need for a broad methodological evaluation of the traits in order to identify the most acceptable of these traits in the different cultures and environments, in addition to determining their appropriate number. In this context, this study is based on the importance of religion in Arab and Islamic culture (Najm 2015), and on considering the religion as a sixth trait. The sixth trait of religion is consistent with the study by Saucier and Goldberg (1998), which considered spirituality as the sixth trait.

\section{Table 1. The Number of Personality Traits in Different Models}

\begin{tabular}{|c|c|c|}
\hline Model and Author & Big Traits & Notes \\
\hline $\begin{array}{l}\text { Two big personality } \\
\text { traits Wiggins (1968) }\end{array}$ & $\begin{array}{l}\text { - Extraversion } \\
\text { - Anxiety }\end{array}$ & $\begin{array}{l}\text { - Many studies have confirmed } \\
\text { both traits. }\end{array}$ \\
\hline $\begin{array}{l}\text { Two big personality } \\
\text { traits, Robertson, } \\
1994\end{array}$ & $\begin{array}{l}\text { - Conscientiousness } \\
\text { - Neuroticism }\end{array}$ & $\begin{array}{l}\text { From BFT, there are two traits } \\
\text { only have un positive effect on } \\
\text { performance. }\end{array}$ \\
\hline $\begin{array}{l}\text { Eysenck's three } \\
\text { factor model, 1967, } \\
1992\end{array}$ & $\begin{array}{l}\text { - Psychoticism } \\
\text { - Extraversion } \\
\text { - Neuroticism }\end{array}$ & $\begin{array}{l}\text { - These three of the five traits } \\
\text { were intercorrelate but not all } \\
\text { BFT. }\end{array}$ \\
\hline $\begin{array}{l}\text { Big five traits, Fiske } \\
\text { (1949) }\end{array}$ & $\begin{array}{l}\text { Extraversion, agreeableness, } \\
\text { conscientiousness, neuroticism, } \\
\text { openness }\end{array}$ & $\begin{array}{l}\text { - The transition from the lexical } \\
\text { hypothesis to the practical } \\
\text { hypothesis, led to the BFT. }\end{array}$ \\
\hline
\end{tabular}


Gadjah Mada International Journal of Business - May-August, Vol. 21, No. 2, 2019

Table 1. Continued

\begin{tabular}{|c|c|c|}
\hline Model and Author & Big Traits & Notes \\
\hline Norman (1963) & $\begin{array}{l}\text { - agreeableness, neuroticism } \\
\text { (emotional stability) } \\
\text { conscientiousness, and culture- } \\
\text { intellect }\end{array}$ & $\begin{array}{l}\text { - Culture is wider as it is a } \\
\text { super-trait while openness } \\
\text { to experience is a trait. }\end{array}$ \\
\hline $\begin{array}{l}\text { Big six traits (HEXACO } \\
\text { Model), Ashton et al. } \\
\text { 2004; Ashon and Lee } \\
\text { 2005; Ashton and Lee } \\
\text { (2008); Lee and Ashton } \\
\text { (2004); Leeb and Ashton } \\
\text { (2014) }\end{array}$ & $\begin{array}{l}\text { - Big five traits plus sixth factor: } \\
\text { honesty-humility }\end{array}$ & $\begin{array}{l}\text { - The HEXACO is an } \\
\text { attempt to provide a } \\
\text { broader view of personalit } \\
\text { by expanding the five } \\
\text { personality traits to includ } \\
\text { religiosity. }\end{array}$ \\
\hline Norman (1963) & $\begin{array}{l}\text { - agreeableness, neuroticism } \\
\text { (emotional stability) } \\
\text { conscientiousness, and culture- } \\
\text { intellect }\end{array}$ & $\begin{array}{l}\text { - Culture is wider as it is a } \\
\text { super-trait while openness } \\
\text { to experience is a trait. }\end{array}$ \\
\hline
\end{tabular}

Alternative Models

Three big traits,

- Self-directedness

Cloninger et al. (1991); - Cooperativeness

Cloninger et al. (1993) - Self-transcendence

- Harm Avoidance

Four big trait, Cloninger - Novelty Seeking

and Svrakic (1997)

- Reward Dependence

- Persistence

- These three traits can predict interpersonal differences in responsiven $\epsilon$ to experimental pain.

- It's a biopsychological model, where the big four traits are moderately stable throughout life.

The Temperament and Character Inventory Revised (TCI-R), Cloninger et al. (1999)

* Four temperaments: Novelty Seeking, Harm Avoidance, Reward Dependence, and Persistence

* Three characters, Selfdirectedness, Cooperativeness, and Self-transcendence.
- The TCI-R has been translated to several languages and cross cultur: contexts with rubest result based on acceptable factor structures. 
Table 1. Continued

\begin{tabular}{|c|c|c|}
\hline Model and Author & Big Traits & Notes \\
\hline $\begin{array}{l}\text { Big six traits, } \\
\text { Church and } \\
\text { Katigbak (1989), } \\
\text { Church and } \\
\text { Katigbak (2002) }\end{array}$ & $\begin{array}{l}\text { - Social potency, responsibility, } \\
\text { emotional control, concern for } \\
\text { others, broad-mindedness, and } \\
\text { affective well-being }\end{array}$ & $\begin{array}{l}\text { - Other six traits have been } \\
\text { developed to describe and } \\
\text { understand the Filipino } \\
\text { personality. }\end{array}$ \\
\hline $\begin{array}{l}\text { Seven big traits, the } \\
\text { Hogan Personality } \\
\text { Inventory: HPI } \\
(1992)\end{array}$ & $\begin{array}{l}\text { - Adjustment, ambition, } \\
\text { sociability, likeability, } \\
\text { prudence, intellectance, and } \\
\text { school success }\end{array}$ & $\begin{array}{l}\text { - HPI is a measure of normal } \\
\text { personality in its social } \\
\text { interactions and in relation to } \\
\text { performance outcomes. }\end{array}$ \\
\hline $\begin{array}{l}\text { Alternative Five- } \\
\text { Factor Model, } \\
\text { Zuckerman et al. } \\
\text { (1991) }\end{array}$ & $\begin{array}{l}\text { - Impulsive sensation seeking, } \\
\text { aggression-hostility, activity, } \\
\text { sociability, neuroticism-anxiety }\end{array}$ & $\begin{array}{l}\text { - This model of personality } \\
\text { traits does not include any } \\
\text { equivalent to openness to } \\
\text { experience. }\end{array}$ \\
\hline $\begin{array}{l}\text { Seven domains of } \\
\text { personality } \\
\text { Temperament and } \\
\text { Character Inventory: } \\
\text { TCI, Cloninger } \\
\text { (1994) }\end{array}$ & $\begin{array}{l}\text { - Harm avoidance, novelty } \\
\text { seeking, reward dependence and } \\
\text { persistence, self-directedness, } \\
\text { cooperativeness, and self- } \\
\text { transcendence }\end{array}$ & $\begin{array}{l}\text { - This is a revised biosocial mode } \\
\text { of personality contains the first } \\
\text { four traits as the temperament } \\
\text { dimensions and the last three as } \\
\text { the character domains. }\end{array}$ \\
\hline $\begin{array}{l}\text { Ten clusters beyond } \\
\text { BFT, Paunonen and } \\
\text { Jackson }(2000)\end{array}$ & $\begin{array}{l}\text { - Religious; deceptive; ethical, } \\
\text { sexy; thrifty; conservative; } \\
\text { masculine-feminine; egotistical; } \\
\text { humorous; risk taking. }\end{array}$ & $\begin{array}{l}\text { - These clusters illustrate that the } \\
\text { five traits are not } \\
\text { comprehensive, and some traits } \\
\text { such as religiosity, ethics are } \\
\text { important pillars of personality }\end{array}$ \\
\hline $\begin{array}{l}\text { Matthews and Oddy } \\
\text { (1993). }\end{array}$ & $\begin{array}{l}\text { - Extraversion: (humorous, } \\
\text { amusing, and popular) } \\
\text { - Ambition (hard-working, } \\
\text { productive, and determined) } \\
\text { - Creativity (imaginative, } \\
\text { inventive, and original) }\end{array}$ & \\
\hline
\end{tabular}


Gadjah Mada International Journal of Business - May-August, Vol. 21, No. 2, 2019

Table 1. Continued

\begin{tabular}{|c|c|c|}
\hline Model and Author & Big Traits & Notes \\
\hline $\begin{array}{l}\text { Chinese Personality } \\
\text { Assessment } \\
\text { Inventory (CPAI), } \\
\text { Cheung et al. (1996) }\end{array}$ & $\begin{array}{l}\text { - Harmony, Ren Qing } \\
\text { (relationship orientation), } \\
\text { modernization, thrift, Ah-Q } \\
\text { mentality (defensiveness), } \\
\text { graciousness, trustworthiness, } \\
\text { face, family orientation, and } \\
\text { somatization (expression of } \\
\text { distress). }\end{array}$ & $\begin{array}{l}\text { - These ten traits can be grouped } \\
\text { into big four traits: } \\
\text { Dependability, Chinese } \\
\text { Tradition, Social Potency, } \\
\text { Individualism. }\end{array}$ \\
\hline $\begin{array}{l}\text { Psychopathology } \\
\text { Five (PSY-5), } \\
\text { Harkness and } \\
\text { McNulty (1994); } \\
\text { Harkness et al. (2002) }\end{array}$ & $\begin{array}{l}\text { Aggressiveness, psychoticism, } \\
\text { disconstraint, negative } \\
\text { emotionality/ neuroticism, } \\
\text { introversion/low positive } \\
\text { emotionality }\end{array}$ & $\begin{array}{l}\text { - Developing BFT for the } \\
\text { personality psychopathology. }\end{array}$ \\
\hline
\end{tabular}

\section{Three Perspectives of the Big Five TRAITS}

Many studies have addressed with both the etic approach (the Big Five traits are universal regardless of the environment, culture or context) and the emic approach (the Big Five traits are culture and contextspecific) (Gurven et al. 2013; Lodhi et al. 2002; Zhou et al. 2009; Triandis and Suh 2002; Cheung et al. 2011). It is the question of Generality (the Big Five traits across cultue) or specificity (different personality traits according to different cultures). In this context of the analysis, we can determine three perspectives to assess the traits of BFT:

- Universal perspective: Aysenck led an ambitious trend to emphasize that the five traits are biological traits. However, his numerous studies have confirmed three more traits that can be considered as well. According to this perspective, the Big Five traits are a universal language of personality, common components, and universal descriptions of personality across cultures and environments (Cheung et al. 1996; ChamorroPremuzic and Furnham 2010). This perspective seeks to develop generalized, imported, and exogenous personality traits. The advocates of the BFT model seek to assert their comprehensiveness, their universality, also to work on finding these traits in other species in an attempt to consider them as biological traits (McAdams and Pals 2006; DeYoung 2010; Zuckerman 1992) and across-cultural traits. Consequently, these traits do not reflect socioeco- 
nomic and cultural factors but rather common universal factors associated with human nature. In the ultimate analysis,

- Local perspective: Ecologies shape cultures and cultures contribute to the formation of personality traits (Triandis and Suh 2002). The meanings of the BFT have been developed in the context of the lexical hypothesis of the English language, and the significance of personality traits has been studied in the context of Western culture. Therefore, The BFT model can be seen as a simplistic western perspective of personality based on context-free traits (Randy et al. 2008; Church and Katigbak 1989; Church and Katigbak 2002). Heine and Buchtel (2009) also confirmed that the BFT model represents the English personality and is more adequate for American participants. In the same context, three studies (Krug and Kulhavy 1973; Cattell et al. 1970 and Plaut et al. 2002 in Rentfrow 2010) also have reported that there are regional differences measured in terms of the BFT. Emphasizing indigenous culture-specific traits and local aspects in culture, many studies on Korean, Indian, Mexican, Filipino and Arabic cultures have confirmed there are many special traits in these cultures that lie beyond the BFT (Miserandino 2012: p. 51; Najm 2015).

Most studies have limited the use of the BFT model to literate and urban populations (Gurven et al. 2013). Therefore, the application of these traits across cultures faces difficulties related to the questionnaire used, the validity and reliability, even in the points of focus on other big traits. There is also the reference-group effect (the tendency for people to respond to items according to implicit standards from their culture) that influences the response to these features (Heine et al. 2002; and Heine et al. 2008). Using the lexical hypothesis in Chinese can lead to different outcomes, as with other big traits (Cloninger 1994; and Thornquist and Kiers 1991) and another number of these traits (ten traits instead of five) (Cheung et al. 1996; and Raad 2009). The same result can be confirmed in the context of Arabic language and culture. According to Karim et al. (2009), the BFT model failed when they were used to measure personality traits in a local (or Islamic) context. According to Mastor et al. (2000), two traits (the Openness and Extraversion traits) from BFT failed to be clear traits of Malay personality. Other traits can be reached, and religiosity is likely to represent a big sixth trait. This perspective seeks to develop particular, contextual, and indigenous personality traits. Finally, a local perspective can provide a contribution to the study of personality on at least two levels. First, it can determine and adopt traits that are more adaptive to the culture-specific group, and these can provide additional predictions of behavior (Ashton and Lee 2008). Within this perspective, we can find the five traits model of Islamic personality proposed by Othman et al. (2014).

- Third perspective in which BFT are still controversial (Costa and McCrae 1992). Although the results of some studies emphasized the importance of cross-cultural traits (Gurven et al. 2013), others emphasized otherwise (McCrae and Costa 2003). According to Eysenck (1998: p. 15), both generality (univer- 
sality) and specificity (locality) have some empirical evidences, and the influence of generality and specificity was approximately equal. Therefore, the Big Five traits remain an open space for further empirical studies to develop our understanding of these traits and improve them to be more comprehensive and universal. This study can be considered as falling within a third perspective that combines generality and specificity and expands the BFT model by adding the sixth trait: religiosity.

In relation to the three perspectives, we can see that there has been a strong tendency to transform BFT into universal traits with biological bases shared by humans regardless of culture, and they are shared with non-humans as well. Zuckerman (1991) who identified four major traits, tends towards considering biological traits. This perspective confirms that all personality differences are biological and these traits originate in the genes (DeYoung, 2010: p. 1166). Although the Big Five traits are important to study our personality, but they must be understood in a psycho-social context rather than a biological context.

\section{Questionnaires for the BFT Model}

Perhaps the hallmark of the BFT model is the multiplicity of questionnaires developed to measure the five traits. These questionnaires are excellent and applicable in some cultural contexts but more problematic in other contexts (Rolland 2002). A study by Hendriks et al. (2003), which covered 13 countries, confirmed results from the BFT model. A study by McCrea (2002) conducted in 36 cultures, and more recently, a study of Schmitt and his colleagues (2007) in fifty-six countries, also led to support for BFT. However, other studies have produced other findings (Thornquist, and Kiers, 1991) or the need for other traits or measures (Cloninger et al. 1991). Rammstedt and his colleagues (2010) provide examples of studies that failed to achieve appropriate results due to different questionnaires (Panayiotou et al. 2004). Other studies that have adopted other traits or other numbers of traits (as in Table 1) produced different results from other studies that supported BFT. Eysenck's study (1992) confirms that three of five traits (neuroticism, extraversion, neuroticism) intercorrelate while the other two (agreeableness and conscientiousness) do not.

In many cases, different studies that use different questionnaires find different results. Some of these different questionnaires are: NEO Personality Inventory (NEO-PI) with 181 items (Costa and McCrae 1985), The NEO Five Factor Inventory (NEO-FFI): 60 items (Costa and McCrae 1989; and Tuominen 2014), TPQue5 with 75 items (Tsaousis and Kerpelis 2004 ), The Big Five Inventory with 44 items (John et al. 1991), NEO Personality Inventory-Revised (NEO-PI-R); 240 items (Costa and McCrae 1992), The Professional Personality Questionnaire: PPQ with 68 items (Kline and Lapham 1990), Zuckerman-Kuhlman Personality Questionnaire: ZKPQ with 68 items (Zuckerman et al.. 1992) (For last two questionnaires, see: Stendorf and Angleitnir 1994), Temperament and Character Inventory (TCI) with three big traits and 35 items (Cloninger et al. 1991) Big Five Inventory (BFI) with 44 items (John et al. 1991), and BFT with 25 items and five item for each factor (Donnellan et al. 2006), The MiniIPIP (The International Personality Item 
Pool) as a short version with 20-item was derived from PIPI-FFM with 50-item (Goldberg 1999; Donnellan et al. 2006), and the 44-item Big Five Inventory: BFI (John and Srivastava 1999). These different questionnaires raise serious questions about these measures and how they affect their results. In fact, these results can be explained by the different questionnaires, as well as by the diversity of environments and cultures that can lead to other traits. Researchers have also differed in formulating the statements or items of trait or even increasing number of these items that cover the trait. Finally, the various questionnaires used to measure the Big Five traits represent a serious problem, although they contributed to enriching the BFT model.

\section{Factors Structure}

To test the BFT model, many statistical instruments have been used such as: exploratory factor analysis (EFA), principal components analysis (PCA), confirmatory factor analyses (CFA), convergent validity, alpha internal consistency, testretest reliability (intra-class correlation) etc. (Johnson 2014; Gurven et al. 2013; Cheung et al. 2011; Aluja et al. 2010; Donnellan et al. 2006; Tsaousis and Kerpelis 2004; Panayiotou et al. 2004; Church and Burke 1994). Factor analysis, especially varimax, is the statistical buzz word in terms of BFT. Varimax is one of the most commonlyused statistical methods as an orthogonal rotation method that produces correlated independent factors with no multi-collinearity problem (Osborne 2015). It is noted in relation to the use of factor analysis, that the results of some studies support the BFT and are consistent with each other in their conclusions (Karim et al. 2009; and Mastor et al. 2000) while others do not
(Eysenck 1967, 1992; and Cloninger and Svrakic 1997). Mastor et al. (2000) study on Malay personality, found that the items under the Openness and Extraversion facets failed to form a clear factor structure. While Aluja et al. (2010) argued that the factor structure with a higher complexity tends to show an acceptable fit.

There is a problem with BFT-oriented studies that ignore other personality traits simply because the researcher does not want to measure other traits such as spirituality or religiosity (O'Donohue et al. 2007: pp x-xi).

In all studies, the factor analysis loadings are significantly different, so it cannot be considered as a personality trait with an equal effect on behavior. This appears in the differences in influence between one study and another, and in one study this effect appears different from one study to another, in the same study, and when there are two versions of the questionnaire. In the Traits Personality Questionnaire 5 (TPQue5), the result of principal components analysis and a varimax rotation is 34 percent of the total variance for the shortened version of TPQue 5 and 56 percent for the full length version. In factor structure, the varimax rotation also yields the most interpretable structure, otherwise orthogonal rotations yielded several differences (Tsaousis and Kerpelis 2004). Apart from the harsh observation of Goldberg (1990) "what one finds depends primarily on how one looks. If that were so, the general goal of developing a scientifically compelling taxonomy of individual differences could be a foolish quest," it is important to emphasize that there is a great and creative effort to increase our understanding of personality description. Moreover, the BFT model already covers the main personality 
traits making it more attractive in personality studies.

\section{Big Five Traits and Performance}

The traits in the BFT model are the antecedents of performance. But with the involvement of individuals in work, these traits can play an influential role in performance. Therefore, important questions can be asked about the relationship between them. Can performance be considered as a function of the BFT traits (i.e. performance $=f(\mathrm{BFT})$ ? Is there a causal relationship between the BFT and high performance? The answer is not conclusive, but it is conditional on these personality traits in relation to other factors. In many studies, there is a positive relationship between all BFT traits and performance and economic success over the life path (Amir et al. 2014). ChamorroPremuzic and Furnham (2010) considered the BFT as good predictors of performance. Big five traits model like Holland's theory of interests and his six personality types (RIASEC) (Armstrong et al. 2008), can be used to determine job preferences. Other studies have confirmed a positive relationship between all or some traits and better performance (Echchakoui 2013; Hogan and Holland 2003; Hurtz and Donovan 2000; Mount and Barrick 1995; Salgado 1997). Also, some studies have demonstrated a positive relationship between some of these traits (but not all). Robertson's study (2001) argues that only two traits (conscientiousness and neuroticism or emotional stability) are aligned with the best performance, but the other three traits (openness, agreeableness, and extraversion) are not important for better performance. Rothstein and Goffin (2006) point out that in fifteen studies there is a relationship between only three traits (conscientiousness, emotional stability and extraversion) and team performance. In relation to religiosity, religious values and rules can be applied for or against what individuals want (Baron 2014). This means that individuals also apply their religious values and rules in dealing with rules of management or performance.

Despite these positive results showing a total or partial relationship between BFT and performance, other studies have revealed other findings that indicate no relationship between them. According to a study by Robie et al. (2005) there is a correlation between extraversion and job performance, whereas there isn't with conscientiousness. Murphy and Dzieweczynski (2005) pointed out that the correlations between all BFT and job performance are very low (close to zero). Hough's study (2011) also confirms that the BFT are not good predictors of performance. Finally, the relationship between the FBTs and the performance cannot be considered a completely positive relationship. In any case, the positive relationship can be overlooked at least between some personality traits and performance.

\section{The Need for a Sixth Trait}

Religion is a spiritual need for human beings and an essential component of every culture in any group. Therefore, there is a real need to reconsider religion and spiritualty in the economy (Nelson 2006), psychology (Emmons and Paloutzian 2003), management (Giacalone and Jurkiewicz 2010) and culture (Paunonen and Jackson 2000). What is more interesting is the growing assertion that man is Homo Economicus who, in his absolute rationality, maximizes his own profit and 
own well-being (Nyborg 2000), and is administrative man who, in his bounded rationality (Simon 1982: 1997), maximizes the gains of all stakeholders, and is also Homo Spiritualis and Homo Religiosus who, in his sublimation of moral and religious values, maximize the meaning and purpose of life for all humanity. Wade (2009) went so far as to talk about "the instinct of faith". However, religion is not only about getting to paradise but it is also about the internal peace of the individual (McBride and Richardson 2012). This study adopts religiosity as a sixth trait along with those traits in the BFT model. The strong assumption of this adoption depends on the fact that religion in many Eastern and possibly nonEastern societies plays an important role in life and culture, and it also greatly influences behavior. This is also evident in Islam, which is the most important and influential dimension in the life and culture of Arab Muslims. Al-Goaib (2003) stressed that, in Islam, religiosity is the commitment to the teachings of Islam, and that there is a relationship between prayer and performance, and students who carry out their religious practices and duties are less likely to cheat during exams. According to Allen (2007), engagemnet in frequent religious activities for individuals is associated with higher satisfaction at work. Nasution (2009) stressed that religious teachings have a great impact on society. While, Njus and Bane (2009) pointed out that intrinsic religiosity plays a role in differences between individuals. In our analysis, the Arab culture seems to be most influenced by the religious dimension (religiosity or faith) (Najm 2015). The religious dimension contributes to the formation of beliefs, values, and behavior of Muslim Arabs. However, religion has been overlooked in national culture models: Hofstede (1980), Hofstede (1988), Schwartz (2006); Globe Project (House et al. 2004); Hall (1981, 1990). Although the BFT model does not recognize religiosity as an independent trait of personality, the Temperament and Character Inventory Revised (TCI-R) included spirituality or the spiritual acceptance facet which is closer to religiosity (Cloninger et al. 1999; Aluja et al. 2010; Aluja and Blanch 2011; Gutiérrez-Zotes et al. 2004). According to studies that review the BFT model, religiosity is associated with high agreeableness and conscientiousness an unrelated to other traits (Saroglou 2002). Anyway, when the traits of BFT do not cover an important personality trait, it must be added to the model, so Zuckerman and Cloninger (1996) added the dimension of spirituality or self-transcendence (closer to the religious dimension) to the personality traits.

In this context, we can say that two views on religiosity have been presented in personality traits studies. The first emphasizes the correlation between religiosity and the BFT, while the second emphasizes that religiosity cannot be reduced to values and social attitudes and must be treated as a trait of personality. McCrea and Costa (1996) have shown that religiosity is associated with two traits in the BFT model: agreeableness and conscientiousness. A study by Hills et al. (2004) also emphasizes that religiosity is strongly associated with neuroticism, while Robbins et al. (2010) have pointed to the relationship of intrinsic religiosity to agreeableness with the explicit assertion that religiosity is a largely independent factor in this relationship. However, this correlation may not be sufficient because it hides the trait of religiosity within other personality traits. This result is consistent with the results of Piedmont's 
study (1999) of spirituality (as an important expression of religiosity) which is a factor independent of the other traits and therefore a sixth trait of personality. Consequently, there is an impact of the 'Big Five' traits on religiosity, at the same time there is an impact of religion on the traits of BFT (Gebauer et al. 2014; Saroglou 2002). Rican and Janosova's study (2010), also shows that spirituality (usually an important presumption of religiosity) is a trait of personality and can be considered a big sixth trait (Piedmont 1999).

This study added to the BFT model a sixth personality trait that is religiosity with six facets: religious faith, rituals, commitment, explicit religious dutifulness, religious work ethic, and spirituality and self-transcendence. This sixth trait depends on the importance of religion. We would like to emphasize that religion played a strong role in the past, and remains influential in the present, and will remain so in the future. That means, religion has a vital role to play in the lives of individuals and societies from historical, phonological, sociological and economic perspectives. In every time and in every land, religion is indispensable in people's lives.

One lesson of history is that religion has many lives. Often, in the past, God and religion have died and been reborn (Durant and Durant 1968). It is the cruelty of life and the depth of the inner experience that make religion a lasting and indispensable resort in people's lives. Whatever our observations on religion at any time and anywhere, they are not enough to make people live without their need for religion. Researchers who sought to confirm that traits in the BFT model are universal traits tended to consider them as genetic traits. In the same context, some researchers of evolu- tionary psychology have asserted that there is a gene of worship or religion (Toates 2011). Also in Maslow's conception, the ultimate human goal of self-actualization and transcendence require the aspiration of people to the idealism attained by religions, and Conscious understanding of satisfaction and movement toward larger and larger includes religion (Maslow 1978, 1999). From a sociological perspective, Weber pointed out that Protestant morality played a catalytic role in the development of society and the emergence of capitalism (McCleary and Barro 2006). In The Protestant Ethic viewed religiosity as an independent variable that could influence economic outcomes (McCleary and Barro 2006). Also from a sociological perspective, and in his book "A secular age" (2007), Taylor pointed out that God is presented in a whole host of social practices (not just the political) and at all levels of society. In his opinion, religion is a set of norms and practices that are overtaken and totally weakened by secularism and the economic and societal roles of government in our modern societies. Yet religion has not diminished or marginalized as expected, and it still has its important functions and roles in the lives of individuals and communities. Religiosity as a sixth trait represents a response to the fact that religion plays a large role in some societies and expresses the uniqueness of these societies in the face of cultural universality.

Islam is one of the world's great religions (O'Neal and Jones 2007). It is the most influential factor in Arab culture and life. This importance was made evident by a study by The PEW Research Forum which involved face-to-face interviews with more than 38,000 people that were recorded in Middle Eastern countries with Arab- 
Muslim majority, Muslims have reported that religion is very important in their lives: Morocco (89\%), Jordan (85\%), Palestinian territories (85\%), Iraq (82\%), Tunisia (78\%), Egypt (75\%), and Lebanon (59\%) (Georgia, 2013). For this reason, this study adopted religiosity as a sixth trait of personality. Religiosity means committing to many things, such as: faith, direct connection to God, committing to the rights of God, reading religious scripture, practicing worship or religious duties, avoiding bad deeds, initiating good things, religious symbols, rituals, language and all other practices that go further (Achour et al. 2015; Achour and Boerhannoeddin 2011; Zullig et al. 2006; Weaver and Agle 2002). ElMenouar's study (2014) identified five dimensions of Islamic religion: basic religiosity, central duties, religious experience, religious knowledge, and orthopraxis. Othman et al. (2014), identified five traits of Islamic personality: 'al-rushd', which include diligence, thrift, moderation and balance; 'bijab', which reflects caring for one's good name, abstaining from committing sins, patience and tawakkal which means being whole-hearted (emotional stability); musyawarah, which means consultation (agreeableness); refraining from talking unproductively and displaying modesty; teamwork, being consultative, participative, and egalitarian; and spirituality, which includes ibadab (prayers), amanab (honesty), and ilmu (knowledge).

\section{Results and Discussion}

This study has confirmed that there are eight important observations (definitions of the traits, history of the BFT; the unity or hierarchy of traits; the number of the traits; three perspectives about the BFT;
BFT questionnaires; BFT and performance; and the need for a sixth trait) that can be made with regard to BFT model. These eight points raise the problem of universalizing one model to explain human personality across borders and cultures, a matter fraught with many dangers, foremost of which is the dissemination of one model to different human groups regardless of environmental, ethnic and cultural differences.

The lexical hypothesis evolved into the BFT model over a relatively long period of time which helped to use these traits extensively in the studies of personality across cultures. But this development has also been accompanied by criticism of multiple aspects of this model. The BFT model has represented an ambitious attempt to provide a single universal interpretation of the human personality regardless of geography, history and cultural diversity; however, this attempt faced many objections. In response to these objections, the researchers developed other models with other personality traits and other numbers of traits (big two, three, four, five, six, seven, and ten traits as shown in Table 1) that are different from the number five as the golden number associated with this model. However, when applying the model in other countries, the model is not valid in the context of non-Anglo-Saxon languages and cultures. This has been confirmed by numerous studies conducted in many countries such as Poland, Czech Republic, Turkey, the Netherlands, Italy, Hungary, South Korea, the Philippines, Spain, Germany, France, Japan, and Taiwan (Saucier and Goldberg 2001; Rolland 2002). The evaluation of BFT model tends to be seen as an Anglo-Saxon cultural view. From another part of the world, China has 
provided other descriptions and traits of Chinese personality. Zhou et al.'s study (2009) identified 3,159 lexical terms to describe Chinese personality, and from them the top 413 terms with highest frequency were used. The results of this study have confirmed that there are other traits that overlap with those in the BFT model.

The BFT model provided a comprehensive and somewhat universal theory of personality and contributed by presenting the traits as more popular descriptions of the personality. This can be explained by the scientific contributions of many researchers which have accumulated over decades to make the BFT model one of the most important theories of personality. In this context, understanding the BFT model with the so-called "Barnum effect" where "people were quick to trust a test that gave general statements about their personalities" (Snyder et al. 1977) contributed to the strength and popularity of BFT.

The basic conclusion is that different questionnaires, different instruments to measure traits, and different cultural contexts can lead to different outcomes. This problem appears in the BFT model and is more pronounced in other models that have used other personality traits. The existence of multiple personality traits models, multiple facets of each trait and multiple questionnaires have contributed to enrich the study of personality, but also create difficulties in studying and reviewing the large number of models, traits and their facets. These difficulties are also associated with the challenges of identifying the most representative personality traits. Therefore, it is necessary to avoid the two extreme points in this area. One one side, a model that cannot be generalized, and, on the other side, many different models con- tributing to the complexity of this scientific topic and reducing the opportunity to benefit from them to understand a complex and puzzling subject such as personality. The ambitious goal of the universal perspective of BFT has contributed to the development of "Periodic Table of Personality" that applies to all human beings, regardless of their cultures, which is similar to "Periodic Table of Chemical Elements" (Woods and Anderson 2016; and Lamiell 2000). According to this perspective, there are values, emotions and behaviors that are similar in all human beings regardless of cultures and environments like chemical elements that are similar everywhere in nature. It is clear from this study that this perspective seems very simplistic, so one recipe for all seems to lack the profound connotation of human diversity which appears in many areas wider than biological diversity. In brief, the personality is a combination of two influences: the genetic influence (which all people share) and the environmental-cultural (which varies according to the diversity of cultures) (Burger 2011: p.13). Therefore, the development of multiple personality traits that respond to diverse environments and cultures can be considered an important enrichment of interpersonal understanding across cultures.

In testing BFT, many statistical methods (EFA, PCA, CFA, and Factor analysis-verimax,) were used, but the lack of consistent results (some results were supportive and others were not) contributed to raising doubts about the universality of these traits and the need to develop them, including the development of other models. Despite the large number of studies and statistical methods used, the results are not final and they have not provided reliable empirical evidence (Rentfrow 2010; Larsen 
and Buss 2014). The same observation can be confirmed with regard to questionnaires used in with BFT model, since multiple questionnaires can lead to different results and possibly reach results that cannot be replicated.

Also, the absence of a causal relationship between all five measles and the multiple outcomes of the relationship between the five characteristics and performance, the individuals involved in corporate policy planning to assess the impact of these characteristics on the performance of workers according to their internal and external environment.

For a long time, psychology had distanced itself from religion and religiosity, and in this period, the BFT model was developed. Although religion is one of the most universal and influential social institutions that contributes to the formation of people's attitudes, values, and behaviors (Farrukh et al. 2016), yet the BFT model overlooked this role.

Today, psychology is like other sciences such as economics and has become more understanding of the interest in religion (McCleary and Barro, 2006; McCleary and Barro, 2003). Therefore, this study supports the adoption of religiosity as a sixth trait, especially in the studying Arab and Islamic personality, where religion is one of the pillars of personality interpretation (Mohd Mahudin et al. 2016; Osman-Gani et al. 2003; Othman et al. 2014). Religion, religiosity, spirituality, religious values, and others that are related to the spiritual needs of man, remain a feature of personality that can not be ignored. Human civilization, with all its fluctuations and challenges, has not been able to weaken the fact that religion has always been a last resort for hu- man being in his search for a great light and Four Noble Truths, (Van Gordon et al. 2015; Thera 2014), for a supernatural hope that may be the sole alternative to despair (Durant and Durant 1968: p. 43), and for perfecting the noblest morals (makarim alakhlaq) (Prophetic Hadith from Islam).

\section{Conclusions}

Some conclusions that can be drawn from studying the BFT model are as follows: the lexical hypothesis has shown that, in different countries, the inventory of dictionary traits to identify adjectival clusters of these traits can reveal new traits that the model could not contain. Paunonen and Jackson (2000) argued that there are other traits (adjectival clusters) beyond BFT that can be considered. The Chinese dictionary (representing the overall treasury of the national language in the country), in the Zhao study for example, explained that there are other different traits (10 traits instead of 5) representing clusters of adjectives in Chinese. This result may apply to any national language in other countries and regions.

There is no one model that can explain personality cross-borders and cultures, and this fact applies to the BFT model. These traits are not universal and are not consistent in all studies. This explains the differences in the importance of these big five traits even in one culture, and they vary in importance from culture to culture. Researchers who developed multiple models of character traits instead of one model provided an important treatment for a standard reductionist view that relies on one model to capture and interpret personality traits in all environments and cultures. 
In many studies, the results of BFT tests were inconsistent (Othman et al. 2014), although appropriate statistical methods such as exploratory factor analysis (EFA), confirmatory factor analyses (CFA), and the factor structure, the results were different, i.e. these tests were supportive of some traits and not supportive of other traits (Robertson, 1994; Mastor et al. 2000). In Costa and McCrae study's (1985) only two traits (neuroticism and extraversion) were more stable, while the other three were not stable over time. These results contributed to criticism of the model (McCrae and John, 1991; Eysenck 1992; Rolland 2002;), and these observations may have contributed to the tendency of researchers to develop other models.

Religiosity is one of the most important traits that has not been taken into account in the BFT model. Despite the longterm confrontation with religion which began with the Renaissance in the fourteenth century and lasted throughout the industrial revolution in the eighteenth century, and the secular era with all its varied influences in the twentieth century (Taylor, 2007). Adding to that atheistic and antireligious communism, the tyranny of material values, the dominance of market laws on our ways of thinking and practices under the influence of "Monsters of the mar- ket: Zombies, vampires and global capitalism" according to (McNally 2011) and where "Profit above people" (Chomsky 2003). Despite that, religion remains a source of moral values, a man's last resort to patience over difficult circumstances and easing tensions, and religiosity remains an important trial of personality. Hence, it is important to develop the model further by adding a sixth trial which is religiosity.

\section{Limitations}

There are some limitations of this study that are useful to refer to. This study is a piece of conceptual research, so it has used other studies to identify important observations on the BFT model. Therefore, the study provides evidence based on the many studies of researchers and the qualitative analysis of the results of these studies. This has been done without conducting a pilot study and quantitative analysis or comparisons between the results of these studies and the results that can be reached when taking into account the important observations provided by this study. This study may provide an incentive for researchers to take advantage of these important observations in future experimental studies based on quantitative analysis and comparison of their studies. 


\section{References}

Aaker, J. L. 1997. Dimensions of brand personality. Journal of Marketing Research XXXIV: 347356.

Achour, M., and A. B. Boerhannoeddin. 2011. The role of religiosity as a coping strategy in coping with work-family conflict: The case of Malaysian women in academia. International Journal of Social Science and Humanity 1 (1): 80-85.

Achour, M., M. R. Mohd Nor, and Y. Z. M. Yusoff. 2015. Islamic personal religiosity as a moderator of job strain and employee's well-being: The case of Malaysian academic and administrative staff. Journal of Religion and Health 54 (2).

Al-Goaib, S. 2003. Religiosity and social conformity of university students: An analytical study applied at King Saoud University. Arts Journal of King Saoud University 16 (1): 51-99.

Allen, B. P. 2006. Personality Theories: Development, Growth, and Diversity. Oxen: Routledge.

Aluja, A., A. Blanch, S. Gallart, and M-J. Dolcet. 2010. The temperament and character inventory revised (TCI-R): Descriptive and factor structure in different age levels. Behavioral Psychology 18 (2): 385-401.

Aluja, A., and A. Blanch. 2011. The five and seven factors personality models: Differences and similitude between the TCI-R, NEO-FFI-R and ZKPQ-50-CC. The Spanish Journal of Psychology 14 (2): 659-666.

Amir, F., F. Naz, S. Q. Hafeez, A. Ashfaq, and Y. H. Dogar. 2014. Measuring the effect of five factor model of personality on team performance with moderating role of employee engagement. Journal of Psychology and Behavioral Science 2 (2): 221-255.

Armstrong, P. I., S. X. Day, J. P. McVay, and J. Rounds. 2008. Holland's RIASEC model as an integrative framework for individual differences. Journal of Counseling Psychology 55 (1): 118.

Ashton, M. C., K. Lee, and L. R. Goldberg. 2004. A hierarchical analysis of 1,710 English personality descriptive adjectives. Journal of Personality and Social Psychology 87: 707-721.

Ashton, M. C., and K. Lee, 2005. Honesty-humility, the Big Five, and the Five-Factor model. Journal of Personality 73: 1321-1353.

Ashton, M. C., and K. Lee. 2008. The prediction of Honesty-humility-related criteria by the HEXACO and five-factor models of personality. Journal of Research in Personality 42: $1216-$ 1228.

Aziz, S., and C. J. Jackson. 2001. A comparison between three and five factor models of Pakistani personality data. Personality and Individual Differences 31: 1311-1319.

Bagby, R. M., P. T. Costa Jr., T. A. Widiger, A. G. Fyder, and M. Marshall. 2005. DSM-IV personality disorders and the Five-Factor model of personality: A multi-method examination of domain and Facet-Level predictions. European Journal of Personality 19: 307-324.

Baron, J. 2014. Moral judgment. In Zamir, Eyal and Teichman, Doron (Eds.): 61-92. The Oxford Handbook of Behavioral Economics and the Law. New York: Oxford University Press.

Briggs, S. R. 1989. The optimal level of measurement of personality constructs. In Buss, D. M., and N. Cantor (Eds.), Personality Psychology: Recent Trends and Emerging Directions: 246260. New York: Springer-Verlag. 
Gadjah Mada International Journal of Business - May-August, Vol. 21, No. 2, 2019

Burger, J. M. 2011. Personality. Belmont: Wadsworth Publishing, Cengage Learning.

Carver, C. S., and M. F. Scheier. 2012. Perspectives on personality. In Boston Barrick, M. R., and M. K. Mount (Eds. 1991), The Big Five Personality Dimensions and Job Performance: A Metaanalysis (In Personnel Psychology: 44, 1-26).

Cattell, R. B., H. W. Eber, and M. M. Tatsuoka. 1970. Handbook for the Sixteen Personality Factor Questionnaire (16 PF). Champaign, IL: Institute for Personality and Ability.

Cervone, D., and L. A. Pervin. 2013. Personality: Theory and Research. New Jersey: John Wiley and Sons, Inc.

Chamorro-Premuzic, T., and A. Urnham.2010. The Psychology of Personnel Selection. Cambridge: Cambridge University Press.

Charles, D. 2013. The Personality Puzzle. New York: W. W. Norton \& Company, Inc.

Cheung, F. M., W. Z. Song, and J. X. Zhang. 1996. The Chinese MMPI-2: Research and applications in Hong Kong and the People's Republic of China: 137-161. In Butcher, J.N. (Eds.), International Adaptations of the MMPI-2: A Handbook of Research and Applications. Minneapolis: University of Minnesota Press.

Cheung, F. M., F. J. R. van de Vijver, and F. T. L. Leong. 2011. Toward a new approach to the study of personality in culture. American Psychologist 66 (7): 593-60.

Chomsky, N., and R. W. McChesney. 2003. Profit Over People: Neoliberalism and Global Order. Naw York: Publisher: Seven Stories Press.

Church, A. T., and M. S. Katigbak. 1989. Internal, external, and self-report structure of personality in a non-Western culture: An investigation of cross-language and cross-cultural generalizability. Journal of Personality and Social Psychology 57: 857 -872.

Church, A. T., and P. Burke. 1994. Exploratory and confirmatory tests of the big five and Tellegen's three- and four-dimensional models. Journal of Personality and Social Psychology 66; 93-114.

Church, A., and M. S. Katigbak, 2002. Studying personality traits across cultures: Philippine Examples. Online Readings in Psychology and Culture, 4(4). . https://doi.org/10.9707/ 23070919.1039, (retrieved Dec, 2017)

Cloninger C. R, T. R. Przybeck, and D. M. Svrakic 1991. The Three-Dimensional Personality Questionnaire: U.S. normative data, Psychological Reports 69: 1047 - 57.

Cloninger C. R, D. M, Svrakic and T. R. Przybeck, 1993. A psychobiological model of temperament and character, Archives of General Psychiatry 50: 975 - 90.

Cloninger, C. R. 1994. Temperament and personality. Current Opinion in Neurobiology 4: 266273.

Cloninger, C. R. and D. M. Svrakic 1997. Integrative psychobiological approach to psychiatric assessment and treatment. Psychiatry 60: 120-141.

Cloninger, C. R., D. M, Svrakic, C. Bayón, and Przybeck T. R. 1999. Measurement of psychopathology as variants of personality (pp. 21-40). In C. R. Cloninger, C. R., D. M. Svrakic, C. Bayón, and T. R. Przybeck (Eds.). Personality and Psychopathology. Washington, DC: American Psychiatric Press.

Cloninger, S. C. 2004. Theories of Personality: Understanding Persons. New Jersey: Pearson Prentice Hall. 
Costa, P. T., and R. R. McCrae. 1988. Personality in adulthood: A six-year longitudinal study of self reports and spouse ratings on the NEO Personality Inventory. Journal of Personality and Social Psychology 54: 853-863.

Costa, P. T., and R. R. McCrae, 1992. Revised NEO Personality Inventory (NEO-PI-R) and NEO Five-Factor Inventory (NEO-FFI) Professional Manual. Odessa FL: Psychological Assessment Resources.

Costa Jr., P.T., and R. R. McCrae. 1995. Domains and facets: hierarchical personality assessment using the revised NEO personality inventory. Journal of Personality Assessment 64 (1): 21-50.

DeYoung, C. G. 2010. Personality neuroscience and the biology of traits. Social and Personality Psychology Compass 4: 1165-1180.

Donnellan, M. B.; F. L. Oswald, B. M. Baird, and R. E. Lucas. 2006. The mini-IPIP scales: TinyYet-effective measures of the big five factors of personality. Psychological Assessment 18 (2): 192-203.

Durant, W., and A. Durant. 1968. The Lessons of History. New York: Simon and Schuster.

El-Menouar, Y. 2014. The five dimensions of Muslim religiosity. Results of an Empirical Study, Methods, Data, Analyses 8 (1): 53-78

Emmons, R. A. and R. F. Paloutzian. 2003. The psychology of religion. Annual Review of Psychology 54: 377-402.

Ewen, R. B. 2003. An Introduction to Theories of Personality. New Jersey: Lawrence Erlbaum Associates, Inc.

Eysenck. H. J. 1992. Four ways five factors are not basic. Personality and Individual Differences, 13(6), 667-673.

Eysenck, H. J. 1998. Dimensions of Personality. New Jersey: Transaction Publishing.

Farrukh, M., C. W. Ying, and N. O. A. Ahmed. 2016. Organizational commitment: Does religiosity matter? Cogent Business and Management. Journal Cogent Business and Management 3 (1).

Feldman, R. S. 2013. Essentials of Understanding Psychology. New York: The McGraw-Hill Companies, Inc.

Gebauer, J. E., B. W. Leidorn, S. D. Gosling, P. J. Rentfrow, M. E. Lamb, and J. Potter. 2014. Cross-cultural variations in Big Five relationships with religiosity: A sociocultural motives perspective. Journal of Personality And Social Psychology 107 (6): 1064-1091.

Georgia, C-S. 2013. Rules and Hofstede's UAI, a study on the Arabic Muslim and European Christian cultures. Journal of Global Politics and Current Diplomacy 1 (1): 79-90.

Giacalone, R. A., and C. L. Jurkiewicz. 2010. Toward a science of workplace spirituality. In Giacalone, R. A., and C. L. Jurkiewicz (Eds.), Handbook of Workplace Spirituality and Organizational Performance. New York: M.E. Sharp, Inc.

Goldberg, L. R. 1981. Language and individual differences: The search for universals in personality lexicons (pp 141-165). In L. Wheeler (Ed.), Review of Personality and Social Psychology 2.

Goldberg, L. R. 1990. An alternative "description of personality": The big- five factor structure. Journal of Personality and Social Psychology 59: 1216-1229. 
Gadjah Mada International Journal of Business - May-August, Vol. 21, No. 2, 2019

Goldberg, L. R. 1992. The development of markers for the Big-Five factor structure. Psychological Assessment 4: 26-42.

Goldberg, L. R. 2001. International personality item pool. In Matthews, G., I. J. Deary, abd M. Whiteman (2003). Personality Traits. Cambridge: Cambridge University Press.

Goldberg, L. R. 1999. A broad-bandwidth, public domain, personality inventory measuring the lower-level facets of several Five-Factor models (pp 7-28). In Mervielde, I. I. Deary, F. De Fruyt, and F. Ostendorf (Eds.), Personality Psychology in Europe 7. Tilburg, The Netherlands: Tilburg University Press.

Gurven, M. R., C. von Rueden, M. Massenkoff, H. Kaplan, and M. L.Vie. 2013. How universal is the Big Five? Testing the Five-Factor model of personality variation among forager-farmers in the Bolivian Amazon. Journal of Personality and Social Psychology 104 (2): $354-370$.

Gutiérrez-Zotes, J. A., C. Bayón, C. Montserrat, J. Valero, A. Labad, C. R. Cloninger, and F. Fernández-Aranda. 2004. Temperament and character inventory revised (TCI-R): Standardization and normative data in a general population sample. Actas Espanolas de Psiquiatría 32: 8-15.

Harkness, A. R., and J. L. McNulty. 1994. The personality psychopathology five (PSY-5): Issue from the pages of a diagnostic manual instead of a dictionary. In Strack, S., and M. Lorr (Eds.), Differentiating Normal and Abnormal Personality. New York: Springer.

Harkness, A. R., J. L. McNulty, Y. S. Ben-Porath, and J. R. Graham. 2002. The Personality Psychopathology Five (PSY-5) Scales: Gaining an Overview for Case Conceptualization and Treatment Planning. Minneapolis. MN: University of Minnesota Press.

Heine, S. J, D. R. Lehman, K. Peng, and J. Greenholtz. 2002. What's wrong with cross-cultural comparisons of subjective Likert scales? The reference-group effect. Journal of Personality and Social Psychology 82: 903-918.

Hills, P., L. J. Francisb, M. Argylea, and C. J. Jacksonc. 2004. Primary personality trait correlates of religious practice and orientation. Personality and Individual Differences 36: 61-73.

Hofstede, G., and M. H.Bond. 1988. Confucius and economic growth: New trends in culture's consequences. Organizational Dynamics 16 (4): 4-21.

Hofstede, G. 1980. Culture's Consequences: International Differences in Work-Related Values. CA: Beverly Hills: Sage.

Hogan, J., and B. Holland. 2003. Using theory to evaluate personality and job performance relations: A Socioanalytic Perspective. Journal of Applied Psychology 88 (1): 100-112.

Hogan, R and Hogan, J. 1992. Hogan Personality Inventory Manual. Tulsa, available at: http:// www.drbobhurley.com (retrieved Dec 14, 2018).

Hough, L.M. 2011. The 'Big Five' Personality variables-construct Confusion: description versus prediction. Human Performance 5 (1-2): 139-155.

House, R. J., P. J. Hanges, M. Javidan, P. W. Dorfman and V. Gupta. 2004. Published Culture, Leadership, and Organizations: The GLOBE Study of 62 Societies. Thousand Oaks, CA: Sage Publications.

Jang, K. L., W .J. Livesley and P.A. Vernon. 1996. Heritability of the big five personality dimensions and their facets: A twin study. Journal of Personality 64 (3): 577-591. 
John, O. P., E. M. Donahue, and R. L. Kentle. 1991. The Big Five Inventory (Versions 4a and 54). Berkeley, CA: University of California, Berkeley, Institute of Personality and Social Research.

John, O. P., and S. Srivastava. 1999. The Big-Five trait taxonomy: History, measurement, and theoretical perspectives (pp. 102- 138). In Pervin, L.A., and O. P. John (Eds.), Handbook of Personality: Theory and rResearch. New York: Guilford Press.

Johnson, J. A. 2014. Measuring thirty facets of the five factor model with a 120-item public domain inventory: Development of the IPIP-NEO-120. Journal of Research in Personality 51: 78-89.

Karim, N. S. A, N.H.A. Zamzuri, and Y. M. Nor. 2009. Exploring the relationship between internet ethics in university students and the big five model of personality. Computers and Education 53 (1): 86-93.

Krueger, R. F., and N. R. Eaton. 2010. Personality traits and the classification of mental disorders: Toward a more complete integration in DSM-5 and an empirical model of psychopathology. Personality Disorders: Theory, Research, and Treatment 1 (2): 97-118.

Lamiell, J. T. 2000. A periodic table of personality elements? The" big five" and trait" psychology" in critical perspective. Journal of Theoretical and Philosophical Psychology 20 (1): 1-24.

Larsen, R. J. and D. M. Buss. 2014. Personality Psychology. New York: McGraw-Hill Education.

$\mathrm{Lee}^{\mathrm{a}}$, K., and M. Ashton. 2004. Psychometric properties of the HEXACO personality inventory. Multivariate Behavioral Research 39 (2): 329-358.

Lee, K., and M. C. Ashton. 2014. The dark triad, the big five, and the HEXACO model. Personality and Individual Differences: 67: 2-5.

Lodhi, P. H., S. V. Deo, and V. M. Belhekar. 2002. The five-factor model of personality: Measurement and correlates in the Indian context. In McCrae, R.R. and J. Allik, (Eds), The FiveFactor Model of Personality Across Cultures (pp 227-248). New York: Springer Science-Business Media.

Maslow, A. H. 1978. Motivation and Personality. New York: Longman.

Maslow, A. H. 1999. Toward a Psychology of Being. New York: John Wiley and Sons.

Mastor, K. A., P. Jin, and M. Cooper. 2000. Malay culture and personality: A big five perspective. American Behavioral Scientist 44 (1): 95- 111.

Matthews, G., and K. Oddy. 1993. Recovery of major personality dimensions from trait adjective data. Personality and Individual Differences 15: 419-431.

McAdams, D. P., and J. L. Pals. 2006. A new big five fundamental principles for an integrative science of personality. American Psychologist 61 (3) (April) $204-217$.

McBride, M. T., and G. Richardson. 2012. The economics of peace and conflict. In Garfinkel, M. R. and S. Skaperda(EDs). The Oxford Handbook of the Economics of Peace (pp. 110-126). Oxford, Oxford University Press.

McCleary, R. M. and R. J. Barro. 2003. Religion and Political Economy in An International Panel. https://scholar.harvard.edu (retrieved May 20, 2017).

McCleary, R. M. and R. J. Barro. 2006. Religion and economy. Journal of Economic Perspectives 20 (2) (Spring): $49-72$. 
Gadjah Mada International Journal of Business - May-August, Vol. 21, No. 2, 2019

McCrae a, R. R., and P. T. Costa, Jr. 1989. Rotation to maximize the construct validity of factors in the NEO Personality Inventory. Multivariate Behavioral Research 24: 107-124.

McCrae, R. R., and P. T. Costa. 1997. Personality trait structure as a human universal. American Psychologist 52 (5): 509-516.

McCrae, R. R., and P. T. Costa, Jr. 2004. A contemplated revision of the NEO Five-Factor Inventory. Personality and Individual Difference 36: 587-596.

McCrae, R. R. 2009. The five-factor model of personality traits: Consensus and controversy. In Corr, Philip J. and G. Matthews (Eds). The Cambridge Handbook of Personality Psychology. Cambridge University Press, New York.

McCrea, R. R. 2002. NEO-PI-R data from 36 cultures: Further intercultural comparisons. In: McCrae, R.R. and Allik, J. (Eds.), The Five-Factor Model of Personality Across Cultures (pp 105-126). New York: Springer Science-Business Media.

McCrae, R. R., and P. T. Costa Jr. 1996. Toward a new generation of personality theories: theoretical contexts for the five-factor model. In Wiggins, J. S. (Ed.), The five-factor model of personality: Theoretical perspectives (pp. 51-87). New York: Guilford.

McNally, D. 2011. Monsters of the Market: Zombies, Vampires and Global Capitalism. Leiden: Brill.

Miserandino, M. 2012. Personality Psychology: Foundations and Findings. Boston: Pearson Education, Inc.

Mohd Mahudin, N. D., N. Mohd Noor, N., M. A. Dzulkifli, and N. S. Janon. 2016. Religiosity among Muslims: A scale development and validation study. Makara Hubs-Asia 20 (2): 109121.

Murphy, K. R., and J. L. Dzieweczynski, J. L. 2005. Why don't measures of broad dimensions of personality perform better as predictors of job performance? Human Performance 18 (4): 343-357.

Najm A. N. 2015. Arab culture diensions in the international and Arab models. American Journal of Business, Economics and Management 3 (6): 423-431.

Nasution, M.E. (2009). Islamic spirit and moral in economics. Journal of International Development and Cooperation 15 (Nos. 1-2: 113-124.

Nelson, R. 2006. Economics as Religion: From Samuelson to Chicago and Beyond. Pennsylvania, The Pennsylvania State University.

Njus, D. M., and C. M. H. Bane. 2009. Religious identification as a moderator of evolved sexual Strategies of men and women. Journal of Sex Research 46 (6): 546-557.

Norman, W. T. 1963. Toward an adequate taxonomy of personality attributes: Replicated factor structure in peer nomination personality ratings. Journal of Abnormal and Social Psychology (66): 574-583.

Nyborg, K. 2000. Homo economicus and homo Politicus: interpretation and aggregation of environmental values. Journal of Economic Behavior and Organization: 305-322.

O'Donohue, W. K.A. Fowler, and S.O. Lilienfild. 2007. Personality Disorders: Toward the DSM$V$. California: Age Publications, Inc. 
ONeal, M. J. and J. S. Jones. 2007. World Religions (1). Detroit: Thomson Gale.

Osborne, J. W. 2015. What is Rotating in Exploratory Factor Analysis? Practical Assessment, Research and Evaluation 20 (2). Available online: http://pareonline.net/getvn.asp?v $=20 \& \mathrm{n}=$ (retrieved Dec 12, 2017).

Osman-Gani, A. M., J. Hashim, and I. Yusof. 2013. Establishing linkages between religiosity and spirituality on employee performance. Employee Relations 35 (4): 360-376.

Othman, A. K. M. I. Hamzah and N. Hashim. 2014. Conceptualizing the Islamic personality model. Procedia: Social and Behavioral Sciences 130: 114-119.

Panayiotou , G, C. M. Kokkinos, and G. Spanoudis. 2004. Searching for the big five in a Greek context: the NEO-FFI under the microscope. Personality and Individual Differences 36: 18411854.

Paunonen, S. V. and D. N. Jackson. 2000. What is beyond the big five? Plenty.! Journal of Personality 68 (5): 821-835.

Plaut, V. C., H. R. Markus, M. E. Lachman. 2002. Place matters: Consensual features and regional variation in American well-being and self. Journal of Personality and Social Psychology 83: 160-184. doi:10.1037/0022-3514.83.1.160.

Raad, B. 2009. Structural models of personality (pp. 127-147). In Corr, P. J. and G. Matthews (Eds), The Cambridge Handbook of Personality Psychology. Cambridge University Press, New York.

Rammstedt, B., L. R. Goldberg, and I. Borg. 2010. The measurement equivalence of big-five factor markers for persons with different levels of education. Journal of Research in Personality 44: 53-61.

Randy, J. R. J. Larsen, and D. M. Buss. 2008. Personality Psychology. Boston: McGraw-Hill.

Raven, B. H. 1992. A power/interaction model of interpersonal influence: French and Raven thirty years later. Journal of Social Behavior and Personality 7: 217-244.

Piedmont R. L. 1999. Does spirituality represent the sixth factor of personality? Spiritual transcendence and the Five - Factor model. Journal of Personality (67): 985-1013.

Rentfrow, P. J. 2010. Statewide differences in personality: Toward a psychological geography of the United States. American Psychologist 65 (6): 548-558.

Rican, P., and P. Janosova. 2010. Spirituality as a basic aspect of personality: A cross-cultural verification of Piedmont's model. The International Journal for the Psychology of Religion 20: (1): 2-13.

Robbins, M. L. J. Francis, D. McIlroy, R. I. Clarke, and L. Pritchard. 2010. Three religious orientations and five personality factors: An exploratory study among adults in England. Mental Health, Religion and Culture 13 (No.7/8): 771-775.

Robertson, I. 2001. Undue diligence. People Management 7 (23): 42-43.

Robie, C., D. J. Brown, and P. R. Bly. 2005. The big five in the USA and Japan. Journal of Management Development 24 (8): 720 - 736.

Rolland, J-P. 2002. The cross cultural generalizability of the five factor of personality (pp 7-28). In McCrae, R. R., and J. Allik (Eds.), The Five-Factor Model of Personality Across Cultures. New York: Springer Science-Business Media. 
Gadjah Mada International Journal of Business - May-August, Vol. 21, No. 2, 2019

Rothstein, M. G., and R. D. Goffin. 2006. The use of personality measures in personnel selection: What does current research support? Human Resource Management Review 16: 155-180.

Saroglou, V. 2002. Religion and the five factors of personality: A meta-analytic review. Personality and Individual Differences 32: 15-25.

Saucier, G., and L. R. Goldberg. 1996. The language of personality: Lexica/ perspectives an the five-factor model (pp 22-50). In Wigging, J. S.(Ed.), The Five-Factor Model of Personality Theoretical Perspective. New York: The Guilford Press.

Saucier, G., and L. R. Goldberg. 1998: What is beyond the Big Five? Journal of Personality 66: 495524.

Schmitt, D., J. Allik, R. R. McCrae, V. Benet. 2007. The geographic distribution of Big Five personality traits: Patterns and profiles of human self-description across 56 nations. Journal of Cross-Cultural Psychology 38 (2): 173- 212.

Schmitt, N. 2004. Beyond the Big Five: increases in understanding and practical utility. Human Performance 17: 347-357.

Schwartz, S. H. 2006. A theory of cultural value orientations: Explication and applications. Comparative Sociology 5 (2/3): 137-82.

Simon, H. A. 1982. Models of Bounded Rationality (Vol. 2). Cambridge, Mass.: MIT Press.

Simon, H. A.1997. Administrative Behavior. New York: Simon \& Schuster.

Snyder, C. R. R. J. Shenkel, and C. R. Lowery. 1977. Acceptance of personality interpretations: The Barnum effect and beyond. Journal of Consulting and Clinical Psychology 45 (1) (Feb): 104-114.

Stendorf, F., and A. Angleitnir. 1994. A comparison of different instruments proposed to measure the Big Five. European Review of Applied Psychology 44 (1): 45-55.

Taylor C. 2007. A Secular Age. Cambridge: The Belknap Press of Harvard University Press.

Taylor, E. 2009. The Mystery of Personality: A History of Psychodynamic Theories. San Francisco: Springer.

Thera, N. 2014. The Heart of Buddhist Meditation. San Francisco: Weiser Book.

Toates, F. M. 2011. Biological Psychology. Harlow: Pearson Education.

Triandis, H.C., and E. M. Suh. 2002. Cultural influences on personality. Annual Review of Psychology 53: 133-60.

Tsaousis, I., and P. Kerpelis. 2004. The traits personality questionnaire 5 (TPQue5): The shortened version of a Big Five measure. European Journal of Psychological Assessment 20 (3): 180-191.

Tuominen, L. 2014. Neurobiological correlates of personality traits: A Study on harm avoidance and neuroticism. Thesis. University of Turku, https://www.doria.fi.

Van Gordon, W., E. Shonin, M. D. Griffiths, and N. N. Singh. 2015. Mindfulness and the Four Noble Truths (pp. 9-19) In Buddhist Foundations of Mindfulness. New York: Springer.

Wade, N.2009. The Faith Instinct: How Religion Evolved and Why it Endures. New York: The Penguin Books.

Weaver, G., and B. Agle. 2002. Religiosity and ethical behavior in organizations: A symbolic interactionist perspective. Academy of Management Review 27 (1): 77-97. 
Widiger, T. A., and S. N. Mullins-Sweatt. 2005.Categorical and dimensional models of personality disorders (pp35-53). In Oldham, J. M., A. E. Skodol, and D. S. Bender(Eds.), Textbook of Personality Disorders. Arlington: American Psychiatric Publishing, Inc.

Wiggins, J. S. 1968. Personality structure. Annual Review of Psychology 19: 293-350.

Woods, S. A. and N. R. Anderson. 2016. Toward a periodic table of personality: Mapping personality scales between the five-factor model and the circumplex model. Journal of Applied Psychology 101 (4) (Apr): 582-604.

Zhou, X., G. Saucier, D. Gao, and J. Liu. 2009. The factor structure of Chinese personality Terms. Journal of Personality 77 (2): 363-399.

Zuckerman, M. 1992. What is a basic factor and which factors are basic? Personality Individual Differences 13 (6): 675-681.

Zullig, K. J., R. M. Ward, and T. Horn. 2006. The association between perceived spirituality, religiosity and life satisfaction: The mediating role of self-rated health. Social Indicators Research 79 (2): 255-274. 